\title{
Real Time System for Blood Analysis
}

\author{
Aditi M. Chavan ${ }^{1}$, Neha R. Bairagi ${ }^{2}$, Shubhadnya Dhumal ${ }^{3}$, Amruta V. Patil ${ }^{4}$ \\ Information Technology, Zeal College of Engineering, Pune India ${ }^{1,2,3,4}$
}

\begin{abstract}
Blood is one of the most crucial element a human needs. And it is the vital element of the life. Now a days, there are way more emergency situations where urgency of blood is there. in this paper, we have proposed a system of blood bank system using Android application. This application will managed and operated on line . in this the admin will access the whole information about the hospitals and the blood banks that have MMU with it, related to donor and the user. via this application you can check quickly the blood banks and the hospitals where the required blood group is needed. This application will give the nearest location of the blood bank or the hospital where the blood is available. This app gives the list of the blood banks and the hospitals in nearby area.
\end{abstract}

Keywords: GSM/GPS Technologies, blood Analysis

\section{INTRODUCTION}

In our nation, only about 2.5 crore units of blood is available from 5.1 crore units. Every day more than 38,100 blood donations are needed. More than 1.1 million new people are diagnosed with serious disease like cancer .The people of cancer needs blood each year, sometimes daily, for chemotherapy. even a single accident can require 101.1 units of blood. This project is aimed to develop an android app and a website which give the user an information about the donors and the blood available in the nearest location. The main motive of this system is to decrease the time delay.
A. Main Objectives
(a) Real time Updations
(b) Real time communication
(c) Less time delay
(d) providing nearest location of blood bank/hospital.

\section{LITERATURE SURVEY}

In "Smart Real-Time Healthcare Monitoring and Tracking System using GSM/GPS Technologies " , Kahtan Aziz , Saed Tarapiah, Shadi Atalla , Salah Haj Ismail[1] , the system can count the heartbeat rate and body temperature . In "Android Blood Bank", Prof. Snigdha1, Varsha Anabhavane2, Pratiksha lokhande3, Siddhi Kasar4, Pranita More5, it is stated that it has become easy to communicate due to mobiles. There are two major factors the web browser and the gps. These functionality is already implemented but was allowed to design by the manufacturers. But now users can access the hardware directly and can design customized applications to develop web and gps services.

In "Online Blood Bank Management System using Android", ashita jain ,amit nirmal,Nitish sapre , Prof Shubhda Mone ., it suggests people to implement Android mobiles for more faster and enhanced communication between the users and the web services.

\section{PROPOSED SYSTEM}

The user has to download the application . After downloading, he/she has to register if he/she is a new user . Registration will have some of the parameters like name, address, contact no , DOB , blood group , email, etc. ,which should be filled up by the new user. If already registered, he/she can log in. the user can now request for the required blood group and his location will be traced. After requesting, in response the user will get the location of the near by blood banks or the hospitals that have the required blood group using the GPS.

The proposed system has the following modules :

User :

a)Acceptor : The user is the acceptor who needs the blood and requests for the required blood group.

b)Donor : The user is the donor who donates his blood to the acceptor who needs the same blood group as of donor. Donor has to register himself first.

Blood Analysis App: It is the app for the users to search the required blood group and displays the nearest location of blood bank or the hospital where the blood of the required blood group is present . Donors can donate the blood as well. 
System Database : It stores all the information regarding the users ,hospitals, blood banks . It has all the necessary information about the donor and the acceptor. Updations can be made in the database.

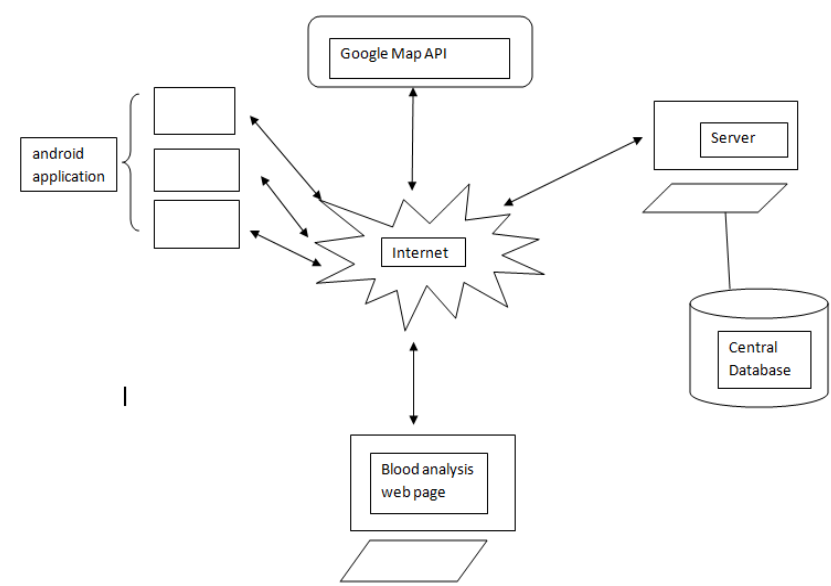

Fig(1): Architecture

Admin: It is the person who monitors the information about the users, blood banks and the hospitals . He can maintain and update the users ,blood bank and hospitals details.

\section{ALGORITHM}

\section{Geo fencing :}

Flowchart
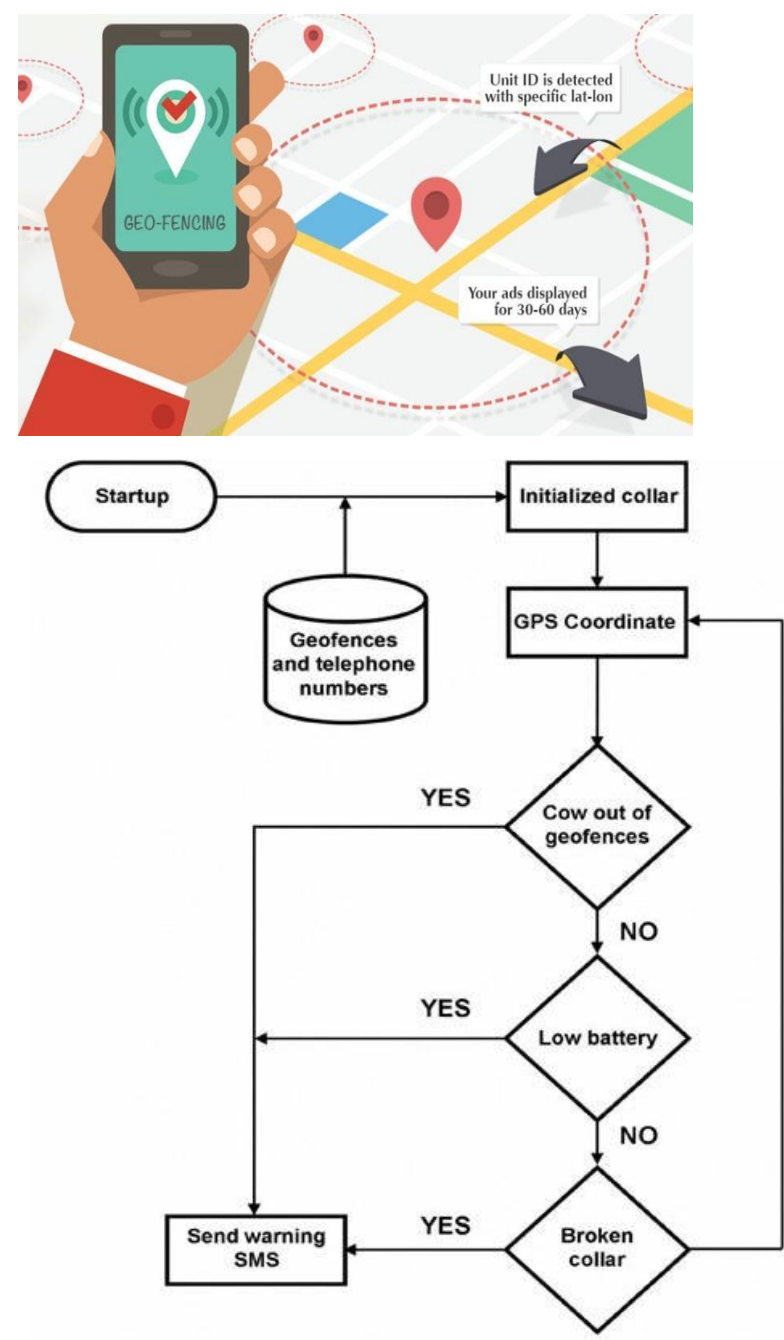


\section{CONCLUSION}

This system is proposed to give a great reliability and efficiency for the users. Now , people can communicate to each and every hospital, blood banks as well as the donors whenever there is urgency for blood. This application provides the nearest blood bank/hospital's location in a short period of time. This will help to overcome death rate issue. Thus the system helps the needy anywhere and anytime.

\section{ACKNOWLEDGEMENT}

It gives a great pleasure in presenting this project paper on "Real Time System For blood Analysis" . We wish o express our immense gratitude to all the people who have invested their knowledge and time for this project. We express our gratitude to our project guide Prof. Amruta Patil, who have supported us and provided us the guidance Authors are thankful to Faculty of Engineering and Technology (FET),Savitribai Phule Pune University,Pune for providing the facility to carry out the research work

\section{REFERENCES}

[1]. Prof. Snigdha1, Varsha Anabhavane2, Pratiksha lokhande3, Siddhi Kasar4, Pranita More5 , "Android Blood Bank".

[2]. Ashita jain ,amit nirmal,Nitish sapre , Prof Shubhda Mone , "Online Blood Bank Management System using Android"

[3]. Kahtan Aziz, Saed Tarapiah, Shadi Atalla, Salah Haj Ismail, "Smart Real-Time Healthcare Monitoring and Tracking System using GSM/GPS Technologies " 